\title{
DISPONIBILIDADE DE MATÉRIA SECA EM PASTAGENS DE CAPIM-ELEFANTE IRRIGADAS ${ }^{1}$
}

\author{
ROGÉRIO DOS SANTOS LOPES ${ }^{2}$ \\ DILERMANDO MIRANDA DA FONSECA ${ }^{3}$ \\ RUBENS ALVES DE OLIVEIRA ${ }^{4}$ \\ DOMÍCIO DO NASCIMENTO JÚNIOR ${ }^{3}$ \\ ALEX CARVALHO ANDRADE ${ }^{5}$ \\ LORILDO ALDO STOCK ${ }^{6}$ \\ CARLOS EUGÊNIO MARTINS ${ }^{6}$
}

\begin{abstract}
RESUMO - Com o objetivo de avaliar os efeitos da irrigação na disponibilidade de matéria seca em pastagens de capim-elefante, cv. Napier, foi conduzido um experimento durante dois anos no Setor de Agrostologia da UFV. A irrigação foi realizada por um sistema de aspersão convencional de média pressão, usando turno de rega variável. Observou-se que, nos dois períodos de seca abrangidos pelo experimento, a irrigação não conseguiu determinar diferenças significativas na disponibilidade de matéria seca do capim-elefante. Por outro lado, quando se avaliaram os resultados acumulados para os períodos de inverno e verão, a disponibilidade de
\end{abstract}

\begin{abstract}
forragem nos tratamentos sob irrigação foi sempre significativamente maior, em razão de a irrigação suprir e manter a umidade do solo em níveis suficientemente adequados para as forrageiras, quando as temperaturas mínimas não foram limitantes ao crescimento, eliminando os efeitos dos veranicos e permitindo manutenção da estabilidade da produção. Conclui-se que a irrigação realizada de forma eficiente e criteriosa pode ser mais uma alternativa, visando ao aumento da produção animal a pasto, pois permite significativos aumentos na produção forrageira, principalmente no verão, quando as temperaturas mínimas não foram limitantes ao desenvolvimento do capim-elefante.
\end{abstract}

TERMOS PARA INDEXAÇÃO: Aspersor, irrigação por aspersão, nitrogênio, Pennisetum purpureum, potássio, produção.

\section{AVAILABILITY DRY MATTER IN ELEPHANT-GRASS PASTURES IRRIGATED}

\begin{abstract}
With the objective of evaluating the effects of the irrigation in the availability of dry matter in elephant-grass pastures, cv. Napier, an experiment was driven for two years in the Section of Agrostologia of UFV. The irrigation was accomplished by a system of conventional aspersion of medium pressure, using turn of watering variable. It was observed that, in the two drought periods embraced by the experiment, the irrigation didn't get to determine significant differences in the availability of dry matter of the elephant-grass.
\end{abstract}

On the other hand, when the accumulated results were evaluated for the winter and summer periods, the forage availability in the treatments under irrigation was always significantly larger, in reason of the irrigation to supply and to maintain the humidity of the soil sufficiently in levels adjusted for the forages, when the minimum temperatures did not limit to the growth, eliminating the effects of the drought stress and allowing maintenance of stability of the production. It was concluded that the irrigation technique conducted

\footnotetext{
1. Parte da tese apresentada à Universidade Federal de Viçosa (UFV), pelo primeiro autor, para obtenção do título de Doutor em Zootecnia. Projeto financiado pela FAPEMIG.

2. Zootecnista. Fiscal Federal Agropecuário/DFPA/MAPA. rogeriolopes@agricultura.gov.br

3. Professor do Departamento de Zootecnia da UFV.

4. Professor do Departamento de Engenharia Agrícola da UFV.

5. Zootecnista. Bolsista de recém-doutor na UNIVERSIDADE FEDERAL DE LAVRAS/UFLA - Caixa Postal 37 37200-000 - Lavras, MG.

6. Pesquisador da Embrapa-Gado de Leite.
} 
in an efficient and discerning way can be more an alternative, seeking to the increase of the animal production at grass, because it allowed significant increases in the forage production, mainly in the summer, where the minimum temperatures did not limit the development of the elephant grass.

INDEX TERMS: Irrigation by aspersion, nitrogen, Pennisetum purpureum, potassium, production, sprinkle.

\section{INTRODUÇÃO}

Uma das principais necessidades da população mundial nos dias atuais é economizar água, para que a diferença entre o consumo total e o que é reposto pelas chuvas/infiltração nos lençóis e aqüíferos subterrâneos, que hoje é de cerca de 160 bilhões de metros cúbicos/ano, diminua progressivamente até o equilíbrio.

Nesse sentido, a utilização da irrigação assume papel central nessa discussão, porque cerca de $40 \%$ dos alimentos no mundo provêm hoje de $17 \%$ de terras agrícolas irrigadas, o que pode determinar dificuldades na negociação de racionamentos na prática da irrigação em culturas e pastagens (NOVAES, 2001).

Em um mundo globalizado e de alta competição, torna-se, assim, cada vez mais necessária a adoção da tecnologia, para obter máximas produções, com o uso mais eficiente de fertilizantes e com a possibilidade do emprego de maior densidade de plantio e do uso de cultivares que respondam melhor à irrigação (AGUIAR, 2001a). Por isso, a prática da irrigação, ao contrário do que se imaginava, tem aumentado entre os produtores $\mathrm{e}$, mais recentemente, entre os pecuaristas, que, junto com o aumento da adubação, estão acreditando nessa nova maneira de conseguir aumentar as taxas de lotações nas pastagens.

Nos Estados de Goiás, Mato Grosso, Bahia e Tocantins, com a utilização da irrigação, tem sido possível manter no inverno até $70 \%$ da lotação do verão, em virtude de as temperaturas de inverno não serem tão rigorosas (AGUIAR, 2001b). Dessa maneira, produtores de leite têm conseguido produtividade de 15.000 a 18.000 litros de leite/ha.ano, normalmente em sistemas de aspersão com canhões. Segundo Vilela et al. (1996), o potencial em pastagens irrigadas é maior que 37.000 litros de leite/ha.ano, como foi obtido pela EMBRAPAGado de Leite em Coronel Pacheco, em pastagens de coastcross.

Cardoso (2001), trabalhando com animais de corte em fase de recria em pastagens de capimMombaça sob irrigação, na região noroeste de Minas Gerais, tem obtido resultados bastante satisfatórios, quando comparados com áreas não-irrigadas, conseguindo lotações de 14 a 16 animais por hectare.
Dessa maneira, a irrigação é capaz de permitir razoáveis ganhos na época seca do ano, além de se apresentar como instrumento para intensificação da produção de forragem no período das águas. No entanto, Maldonado et al. (1997) estimaram uma curva de resposta negativa (quadrática) na produção de matéria seca para as cultivares de capim-elefante irrigado durante o verão, verificando que, com a maior lâmina de água utilizada, essas cultivares apresentaram menor produção. Esse fato pode ter sido decorrente do excesso de umidade, da falta de aeração do solo e da possível lixiviação de nutrientes.

Dessa maneira, com o objetivo de avaliar o efeito da irrigação sobre a disponibilidade de matéria seca ao longo do ano, conduziu-se este experimento manejado, com turno de rega variável, em pastagens de capimelefante adubadas com doses crescentes de nitrogênio e potássio.

\section{MATERIAL E MÉTODOS}

O experimento foi conduzido no Setor de Agrostologia do Departamento de Zootecnia da UFV, entre abril de 1999 a março de 2001. A temperatura média anual de Viçosa é de $19^{\circ} \mathrm{C}$. A umidade relativa do ar é, em média, de $80 \%$ e a precipitação média anual, $1.341 \mathrm{~mm}$, com estações seca e chuvosa bem definidas. O clima é classificado como Cwa, subtropical, com inverno ameno e seco.

A correção da acidez do solo foi realizada com a aplicação de calcário dolomítico, segundo o método do Al, Ca e Mg trocáveis (CFSEMG, 1999). O plantio do capim-elefante (Pennisetum purpureum Schum. cv. Napier) foi realizado em sulcos espaçados de $0,5 \mathrm{~m}$, com adubação fosfatada (superfosfato simples) de $200 \mathrm{~kg} / \mathrm{ha}$ de $\mathrm{P}_{2} \mathrm{O}_{5}$. No ano seguinte, a adubação fosfatada de manutenção foi de $40 \mathrm{~kg} / \mathrm{ha}$ de $\mathrm{P}_{2} \mathrm{O}_{5}$.

Os tratamentos consistiram da aplicação de quatro doses de nitrogênio e potássio, em uma relação $1 \mathrm{~N}: 0,8 \mathrm{~K}_{2} \mathrm{O}$, com e sem irrigação: $-100 \mathrm{~kg} / \mathrm{ha}$ de nitrogênio $+80 \mathrm{~kg} / \mathrm{ha}$ de potássio; - $200 \mathrm{~kg} / \mathrm{ha}$ de nitrogênio + $160 \mathrm{~kg} / \mathrm{ha}$ de potássio; - $300 \mathrm{~kg} / \mathrm{ha}$ de nitrogênio + $240 \mathrm{~kg} / \mathrm{ha}$ de potássio; e - $400 \mathrm{~kg} / \mathrm{ha}$ de nitrogênio + $320 \mathrm{~kg} /$ ha de potássio. 
O delineamento experimental foi o de blocos ao acaso com três repetições, para os tratamentos de sequeiro e irrigados. Cada bloco possuía uma área de $1200 \mathrm{~m}^{2}$, dividida em quatro piquetes de $300 \mathrm{~m}^{2}$, constituindo a unidade experimental. O sistema de pastejo adotado foi o rotativo, com entrada dos animais nos piquetes quando a média da altura da forrageira em todos os tratamentos atingisse $1,70 \mathrm{~m}$, aproximadamente. Os animais permaneceram nos piquetes até a altura residual média de $0,80 \mathrm{~m}$. Durante o período de descanso, os animais foram mantidos em outras áreas, não possibilitando, assim, inferência sobre o desempenho dos animais. Dessa maneira, esses foram usados somente como ferramentas de corte do sistema.

As adubações nitrogenadas (Uréia) e potássicas (Cloreto de potássio) foram realizadas em cobertura após o estabelecimento do capim-elefante e sempre depois do pastejo.

O parcelamento das doses foi diferenciado. Nos tratamentos de sequeiro, a quantidade correspondente a cada dose foi dividida em três partes iguais aplicadas no período das águas, enquanto os tratamentos irrigados tiveram $70 \%$ de sua adubação divididos em três partes iguais no período chuvoso e os $30 \%$ restantes, aplicados no período da seca.

As estimativas de disponibilidade de forragem realizadas dentro de cada período foram conseguidas com a utilização de equações de regressão obtidas a partir da forragem amostrada (corte a $0,80 \mathrm{~m}$ do solo) e das medidas de altura e cobertura realizadas na primeira avaliação de cada período.

A irrigação foi feita por meio de um sistema de aspersão convencional de média pressão. A linha principal do sistema era fixa e constituída por tubos de PVC de 3" com conexão rosqueável do tipo engate rápido. As linhas laterais, também de PVC de 2", com engate rápido, continham cinco aspersores, que forneceram vazão de $2,39 \mathrm{~m}^{3} / \mathrm{h}$. O espaçamento utilizado entre aspersores foi de $18 \times 18$ metros.

O manejo da irrigação foi feito com turno de rega variável, usando-se o método do tanque "Classe A" para estimativa da evapotranspiração de referência, por meio da equação $\left(\mathrm{ET}_{0}=\mathrm{Kt} \mathrm{x} \mathrm{EV}\right)$, em que: $\mathrm{ET}_{0}$ : evapotranspiração de referência, $\mathrm{mm} \mathrm{dia}^{-1}$; Kt: coeficiente do tanque, adimensional; e EV: evaporação no tanque "Classe A", mm dia ${ }^{-1}$.

A evapotranspiração potencial da cultura foi estimada aplicando-se a equação $\left(\mathrm{ETpc}=\mathrm{Kc} \times \mathrm{ET}_{0}\right)$, em que: ETpc: evapotranspiração potencial da cultura, $\mathrm{mm}$ $\mathrm{dia}^{-1}$; e Kc: coeficiente de cultura, adimensional.
O valor do coeficiente de cultura foi de 0,85 , definido para o estádio de desenvolvimento II FAO, citado por Bernardo (1996). A evapotranspiração real da cultura foi obtida pela equação $(E \operatorname{Trc}=\mathrm{Ks} \quad \mathrm{x}$ Etpc), em que: ETrc: evapotranspiração real da cultura, $\mathrm{mm} \mathrm{dia}^{-1}$; e Ks: coeficiente de umidade do solo, adimensional.

O coeficiente de umidade do solo foi estimado aplicando-se a equação (1) proposta por Bernardo (1996), em que: LAA: lâmina de água no solo, mm; e CTA: capacidade total de retenção de água no solo, $\mathrm{mm}$.

$$
\mathrm{Ks}=\frac{\ln (L A A+1,0)}{\ln (C T A+1,0)}
$$

A capacidade total de retenção de água no solo foi calculada por meio da equação (2), em que: Cc: capacidade de campo, \% em peso; Pm: ponto de murchamento permanente, \% em peso; Da: densidade do solo, $\mathrm{g} \mathrm{cm}^{-3}$; e Z: profundidade efetiva do sistema radicular da cultura, $\mathrm{cm}$.

$$
\mathrm{CTA}=\frac{(C c-P m)}{10} \times \text { Da } \times \mathrm{Z}
$$

A capacidade de campo foi determinada por meio do método do equivalente de umidade, e o ponto de murchamento permanente foi obtido com uso do extrator de Richards. A densidade do solo foi determinada em amostras indeformadas, obtidas com amostrador tipo Uhland.

Dessa maneira, a irrigação foi efetuada quando o valor do somatório da evapotranspiração real da cultura, subtraído da precipitação efetiva, foi aproximadamente igual ao valor da capacidade real de água no solo, a qual foi calculada aplicando-se a equação (CRA = CTA x f ), em que: CRA: capacidade real de água no solo, mm; e f: fator de disponibilidade de água no solo, adimensional. No cálculo da CRA, considerou-se $\mathrm{f}=$ 0,5 , para as condições de planta e clima envolvidas no experimento.

O tempo de duração de cada evento de irrigação foi calculado pela relação entre a irrigação total necessária (ITN) e a intensidade de aplicação de água dos aspersores. A ITN foi calculada por meio da equação (3), em que: Pe: precipitação efetiva, mm; e Ea: eficiência de aplicação de água do sistema de irrigação, decimal. 


$$
\mathrm{ITN}=\frac{\sum E T r c-P e}{E a}
$$

A Ea foi calculada aplicando-se a equação (4), em que: $\bar{H}$ : lâmina média colhida, mm; e $H m$ : lâmina média aplicada, $\mathrm{mm}$.

$$
\mathrm{Ea}=\frac{\bar{H}}{H m} \times 100
$$

A determinação da $\bar{H}$ foi obtida por um conjunto de pluviômetros em torno do aspersor central da linha de irrigação. A uniformidade de distribuição de água foi realizada por meio do cálculo do coeficiente de uniformidade de Christiansen (BERNARDO, 1996).

A lâmina total de água aplicada na primeira irrigação foi calculada com base na umidade do solo, determinada por meio do método padrão de estufa, usando-se amostras representativas da camada de $30 \mathrm{~cm}$ de profundidade. Os dados de precipitação pluvial, evaporação, velocidade do vento, umidade relativa e temperaturas médias, mínimas e máximas foram obtidos na Estação Meteorológica Principal da Universidade Federal de Viçosa.

Os dados da disponibilidade de matéria seca total foram processados no Sistema de Análises Estatísticas e Genéticas (SAEG 8.0) e os tratamentos, comparados pelo teste de Tukey, a $5 \%$ de probabilidade.

\section{RESULTADOS E DISCUSSÃO}

Na Tabela 1, observa-se a ausência de dados para os tratamentos de sequeiro, em razão do baixíssimo crescimento, resultante das baixas temperaturas e precipitação do período avaliado, o que não gerou altura mínima de corte para avaliação da produção. Já para os tratamentos irrigados, a elevação nos níveis aplicados de $\mathrm{N}$ e $\mathrm{K}$ somente foram significativos $(\mathrm{P}<0,05)$ na maior dose testada. Esse resultado contraria a expectativa de que a irrigação pudesse potencializar as diferenças entre as doses aplicadas. Essa falta de diferença para as três menores doses ocorreu provavelmente pelo baixo desenvolvimento das plantas submetidas às baixas temperaturas do período, mesmo estando os níveis de umidade do solo adequados ao desenvolvimento.
TABELA 1 - Disponibilidade de matéria seca total (MST) de capim-elefante submetido a diferentes doses de $\mathrm{N}$ e K no período seco do primeiro ano (abril a setembro de 1999).

\begin{tabular}{cc}
\hline $\begin{array}{l}\mathbf{N}+\mathbf{K} \\
\left(\mathbf{k g ~ h a}^{-\mathbf{1}}\right)\end{array}$ & Irrigado \\
\cline { 2 - 2 } & $\mathbf{M S T}\left(\mathbf{k g ~ h a}{ }^{-\mathbf{1}}\right)$ \\
\hline $400+320$ & $7.443 \mathrm{~A}$ \\
$300+240$ & $5.403 \mathrm{AB}$ \\
$200+160$ & $4.177 \quad \mathrm{~B}$ \\
$100+80$ & $4.150 \quad \mathrm{~B}$ \\
\hline
\end{tabular}

Médias seguidas de mesma letra não diferem estatisticamente a $5 \%$ de probabilidade, pelo teste Tukey.

Segundo Witheman (1980), as espécies de clima tropical produzem pouco, quando expostas a temperaturas menores que $16^{\circ} \mathrm{C}$. Além disso, a forrageira ainda estava em fase de estabelecimento, com o sistema de enraizamento pouco desenvolvido, o que comprometeu o crescimento das plantas em todos os tratamentos.

Ao se analisar a Tabela 2, verifica-se que houve efeito significativo $(\mathrm{P}<0,05)$ da adubação e da irrigação na disponibilidade de matéria seca, durante o primeiro ano de experimento, com interação entre esses dois fatores de produção. Assim, a irrigação exerceu maior efeito sobre a produção na presença de maiores doses aplicadas.

A ocorrência de efeito significativo para a interação entre doses de adubo e irrigação, na produção de matéria seca de capim-elefante, comprova a resposta positiva dessa forrageira ao manejo mais intensivo. Essa informação permite afirmar que a aplicação de maiores doses de $\mathrm{N}$ e K nas pastagens, com o intuito de aumento da pressão de pastejo, deve ser acompanhada da irrigação para obtenção de melhores resultados.

Os maiores valores obtidos para as disponibilidades de matéria seca nos tratamentos irrigados estão de acordo com os resultados obtidos por Guelfi Filho (1972), que, irrigando o capim-elefante durante o verão, obteve aumento na produção de matéria seca de $3.590 \mathrm{~kg}$ de $\mathrm{MS} / \mathrm{ha}$ em relação à testemunha, enquanto os aumentos no inverno foram de $1.189 \mathrm{~kg}$ de MS/ha. 
TABELA 2 - Disponibilidade de matéria seca total de capim-elefante cultivado em condições de irrigação e sequeiro, submetido à aplicação de diferentes doses de $\mathrm{N}$ e K no primeiro ano, entre abril de 1999 e março de 2000 .

\begin{tabular}{|c|c|c|}
\hline \multirow{2}{*}{$\begin{array}{l}\mathrm{N}+\mathrm{K} \\
\left(\mathrm{kg} \mathrm{ha}^{-1}\right)\end{array}$} & Irrigado & Sequeiro \\
\hline & \multicolumn{2}{|c|}{ MST (kg ha $\left.{ }^{-1}\right)$} \\
\hline $400+320$ & $46.217 \mathrm{aA}$ & $34.853 \mathrm{aB}$ \\
\hline $300+240$ & $39.503 \mathrm{bA}$ & $30.550 \mathrm{aB}$ \\
\hline $200+160$ & $33.487 \mathrm{cA}$ & $23.250 \mathrm{bB}$ \\
\hline $100+80$ & $24.127 \mathrm{dA}$ & $23.963 \mathrm{bA}$ \\
\hline
\end{tabular}

Médias seguidas de mesma letra minúscula na coluna não diferem estatisticamente a $5 \%$ pelo teste Tukey.

Médias seguidas de mesma letra maiúscula na linha não diferem estatisticamente a $5 \%$ pelo teste Tukey.

A maior disponibilidade de matéria seca de capim-elefante sob irrigação, quando se consideraram os dois períodos, inverno e verão do primeiro ano de experimento, possivelmente esteja relacionada com as características climáticas de Viçosa. No período de outubro a março, época das águas, ocorre aumento de temperatura e precipitação. No entanto, a distribuição irregular das chuvas nos meses do período das águas não foi suficiente para manter níveis de água no solo acima de $50 \%$ da capacidade total de retenção de água no solo. Dessa forma, a utilização da irrigação, mesmo no período das águas, corrigiu a deficiência de água no solo ocasionada pela distribuição irregular das chuvas no período, o que criou condições de umidade favoráveis ao desenvolvimento do capim nos tratamentos irrigados, determinando disponibilidade de matéria seca significativamente maior $(\mathrm{P}<0,05)$ no final do primeiro ano. Assim, Müller (2000) afirma que o fator temperatura perde importância em períodos do ano que possuem temperaturas mínimas acima de $15^{\circ} \mathrm{C}$ e, nessa situação, as condições hídricas assumem papel preponderante na fenologia das plantas.

Os valores de disponibilidade de matéria seca total de capim-elefante para as diferentes doses de $\mathrm{N}$ e $\mathrm{K}$ estudadas, no período de abril a setembro de 2000 (período de inverno) no segundo ano de avaliação, não foram afetados significativamente $(\mathrm{P}>0,05)$ pela irriga- ção, semelhantemente ao ocorrido para o primeiro ano (Tabela 3). As baixas temperaturas ocorridas em Viçosa nesse período, cuja média foi por volta de $12,9^{\circ} \mathrm{C}$, foram preponderantes para o pequeno desenvolvimento do capim-elefante, mesmo sob irrigação.

TABELA 3 - Disponibilidade de matéria seca total de capim-elefante cultivado em condições de irrigação e sequeiro, submetido à aplicação de diferentes doses de $\mathrm{N}$ e K, no período seco do segundo ano, entre abril e setembro de 2000 .

\begin{tabular}{ccc}
\hline $\begin{array}{l}\mathbf{N}+\mathbf{K} \\
(\mathbf{k g ~ h a}\end{array}$ & Irrigado & Sequeiro \\
\cline { 2 - 3 } & \multicolumn{3}{c}{ MST $\left(\mathbf{k g ~ h a}^{-\mathbf{1}}\right)$} \\
\hline $400+320$ & $10.072 \mathrm{aA}$ & $8.739 \mathrm{aA}$ \\
$300+240$ & $9.424 \mathrm{aA}$ & $9.941 \mathrm{aA}$ \\
$200+160$ & $7.871 \mathrm{aA}$ & $5.905 \mathrm{bcA}$ \\
$100+80$ & $6.807 \mathrm{aA}$ & $4.381 \mathrm{cA}$ \\
\hline
\end{tabular}

Médias seguidas de mesma letra minúscula na coluna não diferem estatisticamente a $5 \%$ pelo teste Tukey.

Médias seguidas de mesma letra maiúscula na linha não diferem estatisticamente a $5 \%$ pelo teste Tukey.

Na Tabela 3, observa-se também, efeito significativo das doses de $\mathrm{N}$ e $\mathrm{K}$ sobre a disponibilidade de matéria seca nos tratamentos de sequeiro. Esse efeito é devido, provavelmente, ao resíduo de adubo deixado pelas maiores doses aplicadas no período das águas anterior, pois somente os tratamentos de sequeiro receberam toda a adubação no verão. No entanto, essa diferença significativa para doses de $\mathrm{N}$ e $\mathrm{K}$ pode ser atribuída à falta de água, determinando maior utilização do carbono para o crescimento radicular, como também para o desenvolvimento de pêlos radiculares. Segundo Marcschner (1993), o baixo conteúdo de água no solo prejudica o alongamento da raiz, como também diminui a absorção de nutrientes, embora parte desses efeitos negativos sobre a densidade específica e o alongamento de raiz possa ser compensada por aumento do desenvolvimento de pêlos radiculares em solos secos. Além disso, Braga (1995) afirma que o K estimula o grau e a extensão da ramificação radicular. Essa maior penetração radicular proporciona, em geral, melhor acesso à umidade para as plantas. Assim, o provável 
maior desenvolvimento de raiz das plantas não irrigadas neste trabalho pode ter permitido a captação de maiores quantidades de nutrientes no período seco do ano de 2000.

$\mathrm{Na}$ Tabela 4, observa-se que houve efeito significativo da adubação e da irrigação, à exceção das menores doses dos fertilizantes aplicados, sobre a disponibilidade de matéria seca total de capim-elefante, no período de abril de 2000 a março de 2001 (períodos de inverno e verão). Esse pronunciado crescimento na produção da pastagem irrigada foi devido ao aumento de temperatura e à manutenção de níveis de umidade adequada no solo. Esses resultados comprovam a afirmação de Andrade (1972), de que é possível obter incrementos superiores a $25 \%$ na produção de matéria seca em pastagens de capim-elefante irrigadas no verão.

TABELA 4 - Disponibilidade de matéria seca total de capim-elefante cultivado em condições de irrigação e sequeiro, submetido à aplicação de diferentes doses de $\mathrm{N}$ e K no segundo ano, entre abril de 2000 e março de 2001 .

\begin{tabular}{|c|c|c|}
\hline \multirow{2}{*}{$\begin{array}{l}\mathbf{N}+\mathrm{K} \\
\left(\mathrm{kg} \mathrm{ha}^{-1}\right)\end{array}$} & Irrigado & Sequeiro \\
\hline & \multicolumn{2}{|c|}{$\operatorname{MST}\left(\mathrm{kg} \mathrm{ha}^{-1}\right)$} \\
\hline $400+320$ & $101.755 \mathrm{aA}$ & $76.016 \mathrm{aB}$ \\
\hline $300+240$ & 83.384 bA & $71.371 \mathrm{aB}$ \\
\hline $200+160$ & $62.811 \mathrm{cA}$ & $43.755 \mathrm{bB}$ \\
\hline $100+80$ & $47.807 \mathrm{cA}$ & $41.228 \mathrm{bA}$ \\
\hline
\end{tabular}

Médias seguidas de mesma letra minúscula na coluna não diferem estatisticamente a $5 \%$ pelo teste Tukey.

Médias seguidas de mesma letra maiúscula na linha não diferem estatisticamente a $5 \%$ pelo teste Tukey.

No segundo ano de experimento, a resposta do capim-elefante à irrigação foi maior do que no primeiro ano, por causa da menor precipitação pluvial ocorrida naquele ano, ocasionando expressivo déficit de umidade no solo. Adicionalmente, as maiores temperaturas observadas no verão do segundo ano, comparativamente ao primeiro, contribuíram para acentuar a resposta do capim-elefante à irrigação.

Loomis et al. (1971), citados por Müller (2000), afirmam que sob quaisquer níveis de estresse hídrico, há maior e mais rápida redução no crescimento da parte aérea em relação ao sistema radicular. Da mesma maneira, Dias Filho et al. (1989) afirmam que pequenas quedas na umidade do solo podem ter, em curtos espaços de tempo, efeito significativo sobre a elongação foliar, sobre o número de folhas e sobre a produção de matéria seca, mesmo sob condições satisfatórias de fertilidade do solo.

\section{CONCLUSÕES}

O manejo adequado da irrigação, juntamente com o aumento da adubação, não foram suficientes para promovererm incrementos significativos na disponibilidade de matéria seca do capim-elefante no período seco, em razão principalmente, das baixas temperaturas ocorridas no período.

A utilização da irrigação, apesar de não eliminar o efeito da estacionalidade de produção do capimelefante, permitiu uma antecipação do período de crescimento das plantas, quando a temperatura não foi limitante, ocasionando aumento significativo da disponibilidade de forragem ao longo do ano, além de assegurar a estabilidade da produção no verão.

\section{REFERÊNCIAS BIBLIOGRÁFICAS}

AGUIAR, A. de P. Manejo de pastagens. Disponível em: <http://www.cpt.com.br/revista/mattec/0190.asp>. Acesso em: 07 out. 2001a.

AGUIAR, A. de P. A irrigação de pastagens no Brasil. Disponível em: <http://www.cpt.com.br/revista/ mattec/0221.asp>. Acesso em: 25 out. 2001b.

ANDRADE, J. M. de S. Efeito das adubações química e orgânica e da irrigação sobre a produção e valor nutritivo do capim-elefante "mineiro" (Pennisetum purpureum, Shum.) em latossolo roxo distrófico do município de Ituiutaba, Minas Gerais. 1972. $42 \mathrm{f}$. Dissertação (Mestrado) - Universidade Federal de Viçosa, Viçosa, 1972.

BERNARDO, S. Manual de irrigação. 6. ed. Viçosa: UFV, 1996. 657 p.

BRAGA, J. M. Curso de fertilidade e manejo do solo: módulo 08, potássio. Brasília, DF: [s.n.], 1995.

CARDOSO, G. C. Alguns fatores práticos da irrigação de pastagens. In: SIMPÓSIO DE PRODUÇÃO DE GADO DE CORTE, 2., 2001, Viçosa. Anais... Viçosa: UFV, 2001. p. 243-260. 
COMISSÃO DE FERTILIDADE DO SOLO DO ESTADO DE MINAS GERAIS. Recomendação para o uso de corretivos e fertilizantes em Minas Gerais: $4^{\mathrm{a}}$ aproximação. Lavras, 1999. 176 p.

DIAS FILHO, M. B.; CORSI, M.; CUSATO, S. Respostas morfológicas de Panicum maximum Jacq. cv. Tobiatã ao estresse hídrico. Pesquisa Agropecuária Brasileira, Brasília, DF, v. 24, n. 7, p. 893-898, 1989.

GUELFI FILHO, H. Efeito da irrigação sobre a produtividade do capim-elefante (Pennisetum purpureum Schum.) variedade napier. 1972. 77 f. Tese (Doutorado) - Escola Superior de Agricultura Luiz de Queiroz, Piracicaba, 1972.

MALDONADO, H.; DAHER, R. F.; PEREIRA, A. V. Efeito da irrigação na produção de matéria seca do capim-elefante (Pennisetum purpureum, Schum) em Campos dos Goytacazes, RJ. In: REUNIÃO ANUAL DA SOCIEDADE BRASILEIRA DE ZOOTECNIA, 34., 1997, Juiz de Fora. Anais... Juiz de Fora: SBZ, 1997. p. 216-218.
MARCSCHNER, H. Mineral nutrition of higher plants. 2. ed. San Diego: [s.n.], 1993.

MÜlleR, M. dos S. Desempenho de Panicum maximum (cv. Mombaça) em pastejo rotacionado, sob sistema de irrigação por pivô central, na região de cerrado. 2000. Dissertação (Mestrado) Escola Superior de Agricultura Luiz de Queiroz, Piracicaba, 2000.

NOVAES, W. Os dramas da irrigação. Disponível em: <http://www.estado.estadao.com.br/editorias/00/ 09/08/aberto001.html>. Acesso em: 25 out. 2001.

VILELA, D.; ALVIM, M. J.; CANTOS, F. Produção de leite de vacas Holandesas em confinamento ou em pastagens de Coastcross. Revista da Sociedade Brasileira de Zootecnia, Viçosa, v. 25, n. 6, p. 1228-1244, 1996.

WHITHEMAN, P. C. Tropical pasture science. New York: Oxford University, 1980. 392 p. 